\title{
Modelling of environmental load on cultural heritage object and monitoring protection at local level
}

\author{
Veronika Petráňová, Jaroslav Valach, Sergii Kuznetsov, Stanislav Pospíšil
}

\begin{abstract}
This paper deals with an experimental investigation of the future environmental load on the medieval mosaic of the Last Judgement located at the entrance to St. Vitus cathedral in the Prague castle. The mosaic suffers from seasonal changes of the weather pattern including rains and their acidity, the deposition of dust and soot particles from polluted air as well as freeze-thaw cycles. These phenomena influence the conservation state of the mosaic. The tesserae composing the mosaic are mostly made from glass prone to weathering. In order to establish a procedure for an appropriate maintenance, the relation between various weather scenarios and their effect on the mosaic was investigated. At the same time a local method for evaluating a suitable protective coating was developed. Both methods will contribute to better care for the mosaic and also to improve visitors' aesthetical experience.
\end{abstract}

Keywords-medieval mosaic, weathering, degradation, monitoring, protection, climatic tunnel

\section{Introduction}

The mosaic of the Last Judgement is a unique mosaic created at the end of the xiv century by Venetian craftsmen, following a direct order of king and Emperor Charles IV. The mosaic is placed on the southern entrance to St. Vitus Cathedral in the Prague Castle. Because of its uniqueness and mastership of execution the mosaic is on the list of protected cultural heritage of the Czech Republic. In the course of history the existence of the mosaic was turbulent. It was several times removed from the façade and its maintenance was rather neglected. Nevertheless the environmental influence observed in previous epochs was not so striking [1].

\section{Veronika Petráňová}

Institute of Theoretical and Applied Mechanics, Academy of Science The Czech Republic

Jaroslav Valach

Institute of Theoretical and Applied Mechanics, Academy of Science The Czech Republic

Sergii Kuznetsov

Institute of Theoretical and Applied Mechanics, Academy of Science The Czech Republic

Stanislav Pospíšil

Institute of Theoretical and Applied Mechanics, Academy of Science The Czech Republic
This fact can be attributed to the limited population and consequentially to the limited volume and concentrations of emissions from burning wood. The situation radically changed in the half of nineteenth century as coal burning for heating and steam engines became widespread. In addition since the beginning of the twentieth century burning of other types of fossil fuels in engines of internal combustion caused a considerable increase in air pollution.

Oxides, like sulfuric ones, combine with raindrops producing diluted acids, generally called acidic rain. The rain attacks the glass pieces of the mosaic, accelerating the deterioration process induced by water itself. Although this might seem as in contrast to the well-known chemical stability of glass, it should be underlined that the mosaic tesserae under analysis were originally produced with a different technology. Pure glass made from silica oxide is chemically resistant and stable, but it melts at high temperature. This temperature can be easily reached nowadays but for the medieval technologist such a high melting point represented an unsurpassable obstacle. To cope with this difficulty soda and lime were added to the mixture to decrease the melting temperature of the glass to a level easily accessible also with a medieval technology. Unfortunately the technological advantage of having a low melting point is counterbalanced by a lower environmental resistance of glass. The salts tend to dissolve, leaving the glass surface exposed and prone to further attack and degradation. The surface damage manifests itself visually as a loss of gloss and saturation of color accompanied by the presence of a whitish powder responsible for light scattering. This process of degradation is known for more than a century and several protection plans were devised to stop it including the covering of the glass with a transparent layer able to eliminate the access of water. Unfortunately such protective coating proved to be degradable by the effects of the environment; being mostly of polymeric nature the layer suffered from the influence of light and especially its UV component. Recently a hybrid coating based on several layers differing in composition was successfully applied with the outermost layer designed for a periodical reapplication. However due to the interruption of the production of such coating material it was necessary to individuate an alternative solution. The scope of the project here presented, which is now close to its end, was indeed to find a reliable replacement for the protective coating of the mosaic. The project aims at providing an optimal solution for the external protective layer as well as at establishing a procedure for a correct periodical monitoring and for an appropriate analysis of the interaction between the environment and the mosaic [2]. This paper focuses specifically on the latter two goals. 


\section{Methods and Results}

\section{A. Experiments at climatic tunnel}

In the last few years a unique "environmental" wind tunnel was built at CET center of ITAM in Telč, Czech Republic. The tunnel allows replicating the environmental load on models of real structures. More specifically the tunnel enables to experimentally test models up to two meters wide and about two meters high. It also permits to control wide ranges of temperature, wind speed and artificial precipitation either in the form of rain or snow. All these variables can be combined into many scenarios which help simulating the interaction between the model of structure and the environment [3].

\section{B. Experimental investigation of interaction between scale model and environment}

In order to perform the tests a scale model of St. Vitus cathedral was build. Firstly all available drawings of the cathedral were transformed into a $3 \mathrm{~d}$ computer model. In the second step the $3 \mathrm{~d}$ surface model was corrected to topologically well-defined sides and volumes, which was a necessary prerequisite for creating a physical model using the $3 \mathrm{~d}$ printer. Considering its final size, the model had to be divided into subsections which were then glued together. In order to fit the scale model into the experimental section of the tunnel, a scale 1 to 200 was used. Such scale was suitable to study in detail the main characteristics of the cathedral interaction with the environment and the pressure distribution around the object by means of pressure coefficient (see Fig. 1). In this way, the locations with negative pressure (suction) can be identified, suggesting the spots where the degradation on the cement joints may occur.

In order to reproduce the real airflow over the object also its surroundings had to be included into the physical model. As the cathedral is located in the central part of the Prague Castle, this also needs to be part of the study. The castle itself sits on the top of small hill, meaning that the wider surroundings can be neglected and considered only into the conditioned airflow including surface boundary layer. Complying with all such requirements the final model of the cathedral was $100 \mathrm{~cm}$ long and about $50 \mathrm{~cm}$ high (see Fig. 2). In addition to the investigations related to the influence of surrounding buildings, the orientation of the cathedral to wind flow (Fig. 3) and the intensity of driven rain, also the local dynamics of the interaction between droplets and the mock up mosaic was observed. The fluctuation in direction and velocity of drops revealed the need for a careful maintenance of cement between the tesserae.

\section{Material Characterization}

The study of the model is complemented with the surface characterization at microscopic level. This is the real scale at which usually the degradation processes occur. Therefore investigations capable of describing the decay prior it is noticeable for human eye are of high importance. In order to achieve this goal, several techniques including scanning electron microscopy (SEM), nanoindentation and surface reflectivity measurement were utilized.

\section{SEM Investigation}

The surface degradation of polymeric coating and lowgrade glass was studied in the MIRA II LMU scanning electron microscope enabling the visualization of surface changes after the exposition to an aggressive environment. Specimens were investigated in the secondary electron mode at $7 \mathrm{kV}$ accelerating voltage and low probe current, ensuring low penetration depth of primary electrons and thus more realistic record of surface topography. The results are summarized in the Fig.4a-f. Contrary to the reference, smooth surface specimen (Fig. 4a and 4d), the weathered surfaces after 3 and 5 weeks, shown respectively in Fig.4b,c,e and f , present a gradually increasing damage over time.

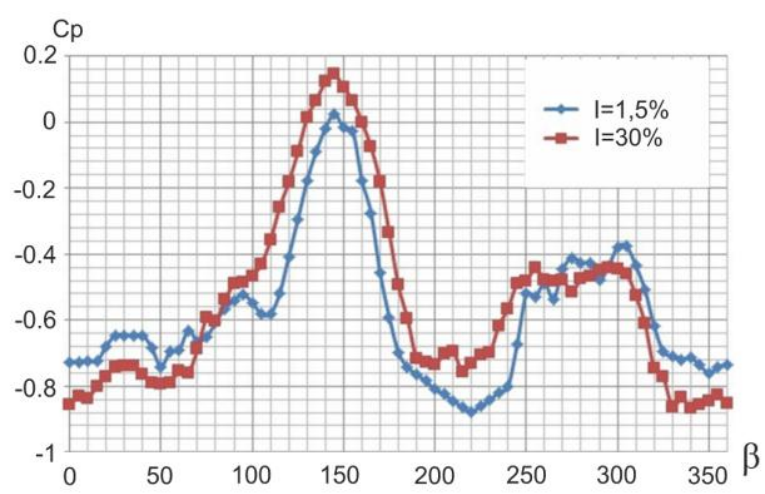

Figure 1. Pressure coefficient at one place of the cathedral as a function of the wind incidence angle.

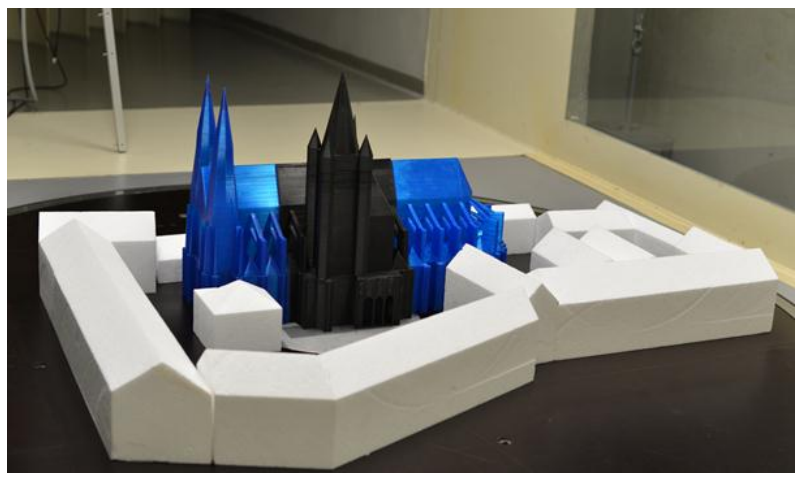

Figure 2. Experimental investigation of local influence of driven rain. The black part of the model contains is the one where the mosaic is at the prototype.
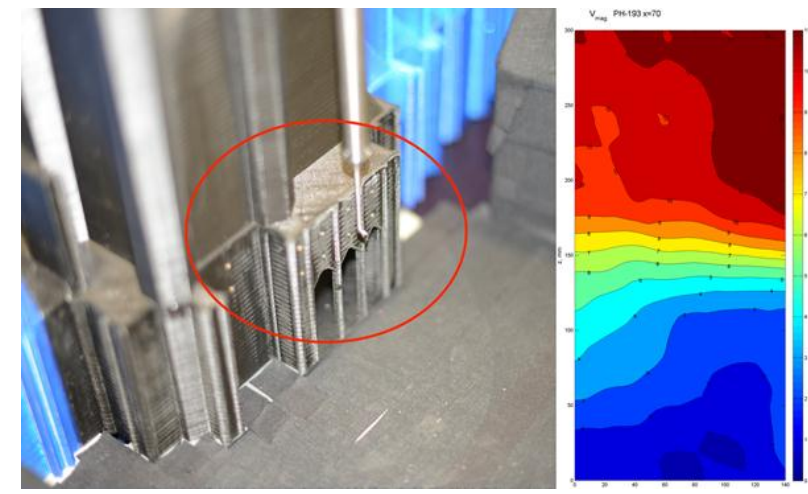

Figure 3. Left: Pressure holes connected to the pressure transducers. Right: Wind velocity profile at the mosaic area. 


\section{Nanoindentation}

Hysitron TI-750 was used to investigate the change of mechanical properties of the coating surface as an indication for degradation processes altering the chemical and physical structure of the polymeric chains constituting the coating. It was found that the weathering effect on the elastic modulus is limited and rather reflects local variations in stiffness [4, 5]. On the other hand there is a well- established correlation between the degree of weathering and correspondent measured nanohardness (Fig. 5).

\section{Reflectance Measurement}

Although nanoindentation is a great technique for characterizing the mechanical properties of the protective coating, some uncertainty due to the localized nature of the measurement remains. Therefore another technique able to investigate a larger area at once was developed. It exploits the relation between the changes of local surface topography and the change of visual appearance of the surface [6]. In other words as the surface wrinkles with aging, the surface alters from specular to diffuse. This process can be measured by custom-built device. The device measures reflectance (a fraction of reflected radiation to incident radiation) in various directions and it combines the gathered measurement into a map.
The parts of the "reflectance map" where the change from specular to diffuse surface is the most pronounced can be used as an indicator of surface degradation state (Fig. 6).

\section{Conclusion}

Experimental investigation on the scale model in the climatic tunnel represents a novel tool capable of indicating important processes influencing the preservation of historical monument under the effects of the environment.

The investigation in the climatic tunnel helps pinpointing the environmental condition that can be detrimental to the conservation of the mosaic. This allows to schedule a special inspection of the mosaic after a selected weather pattern. Furthermore the surface characterization helps to maintain and check the conditions of the protective layer at material level. It yields useful insights into processes happening during weathering as shown in the SEM investigation section of the paper.

Methods like nanohardness measurement or reflectance measurement can be used to document the state of conservation of the coating and as an early warning technique.

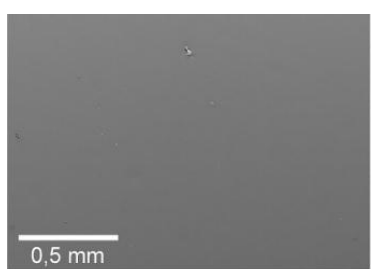

a

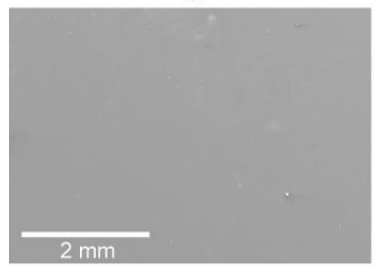

d

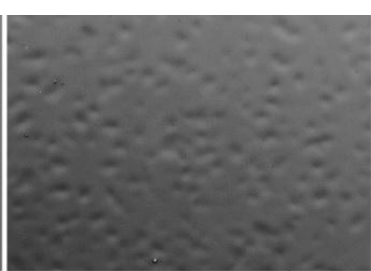

b

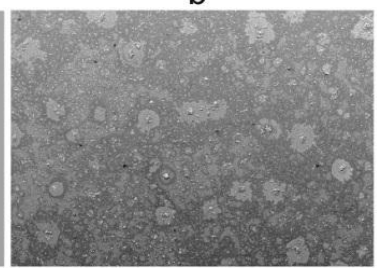

e

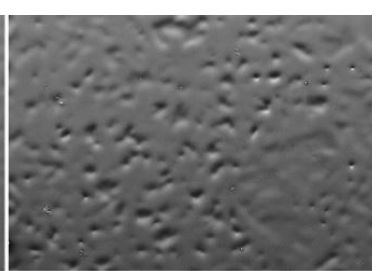

C

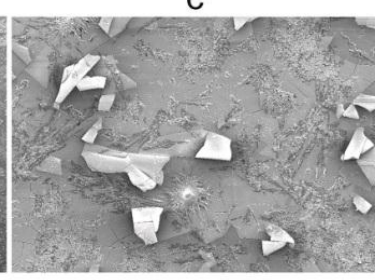

f

Figure 4. SEM micrographs of surfaces of polymeric coating ( $b$ and $c$ ) and low-grade glass (e and f) subjected to accelerated weathering.
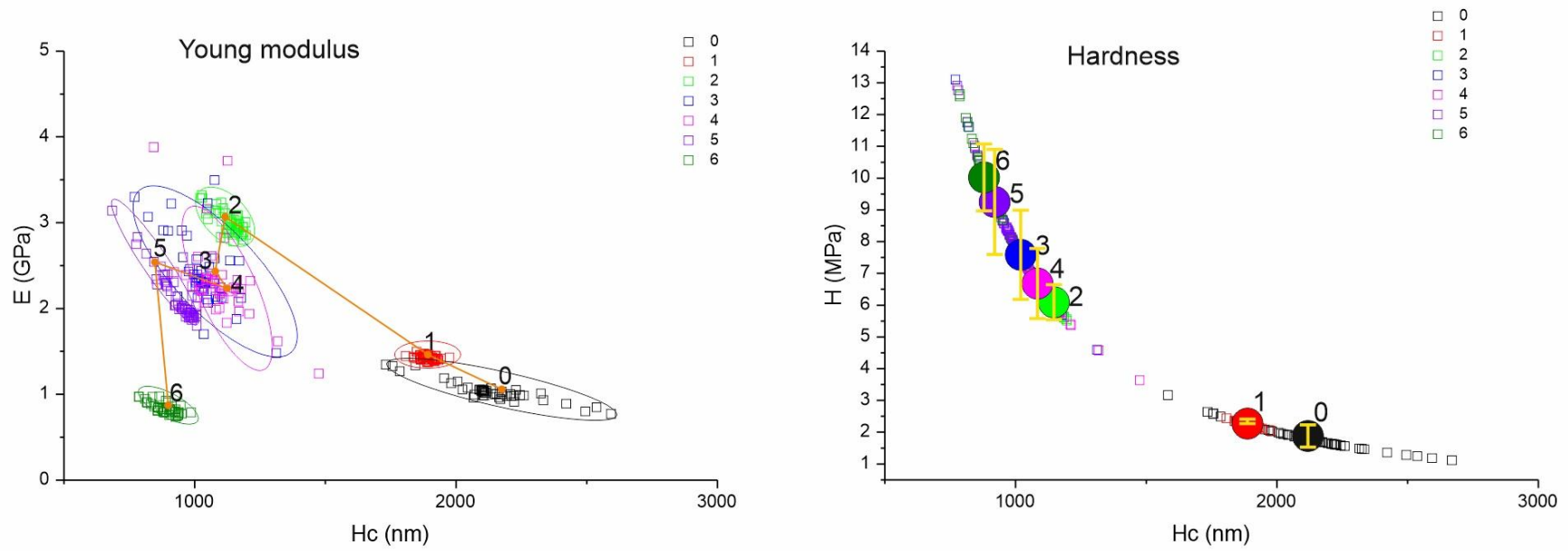

Figure 5. Dependence of Young modulus E (GPa) - left and hardness H (MPa) - right on the displacement Hc (nm). 

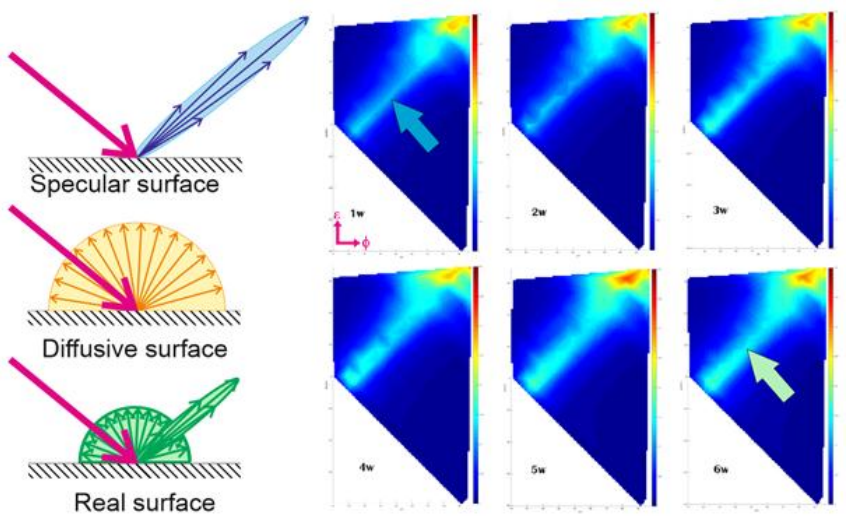

Figure. 6. Schematic representation of distribution of reflected light from various types of surfaces (left); (right) measured "reflectivity maps" for coatings of different duration of aging. The arrows indicate widening of intensity profile for weathered coating (light - green arrow) in comparison to unweathered coating (blue arrow).

\section{Acknowledgment}

Presented research is the part of the project \#DF12P01OVV017 supported by the Czech Ministry of Culture entitled: "Technology of maintenance and conservation of the Last Judgment mosaic and methods of medieval and archaeological glass conservation". The authors thank the researchers Mgr. Vladimír Kocour and Dr. Petr Šašek for reflectometry and nanoindentation analyses.

\section{References}

[1] F. Piqué and D. Stulík. "Conservation of the Last Judgement mosaic, St. Vitus Cathedral, Prague". Los Angeles, Getty Conservation Institute, 2004.

[2] B. Holubová, Z. Zlámalová Cílová, I. Kučerová and M. Zlámal, "Weatherability of hybrid organic-inorganic silica protective coatings on glass", in Prog. Org. Coat. 88, 2015, pp. 172-180.

[3] Kuznetsov S. Pospíśil S. Král R.: CET Climatic wind tunnel for wind engineering tasks 7, EEBO, 2014 - Environmental Effects on Buildings and People, Krynica, Poland

[4] Joslin, D. L., and W. C. Oliver. "A new method for analyzing data from continuous depth-sensing microindentation tests." Journal of Materials Research 5, no. 01 (1990): 123-126.

[5] S. Chen, L. Liu and T. Wang, "Investigation of the mechanical properties of thin films by nanoindentation, considering the effects of thickness and different coating-substrate combinations", in Sur. Coat. Tech., 191, 2005, pp. 25-32.

[6] H. E. Bennett and J. O. Porteus, "Relation between surface roughness and specular reflectance at normal incidence", in J. Opt. Soc. Am., 51, 1961, p. 123.

About Authors: MSc. Petráňová works as SEM operator at the ITAM AS CR, v.v.i. and is PhD student at Faculty of Civil Engineering at CTU University in Prague. Dr. Valach is Head of Laboratory of optical methods of ITAM AS CR, v.v.i., his major interest is development and application of custom-built optical methods in protection of cultural heritage. Assoc. Prof. Pospíśil is deputy director at ITAM AS CR, v.v.i., together with Prof. Kuznetsov, Head of Climatic wind tunnel laboratory in Centre of Excellence in Telč, are interested in research in engineering problems within civil engineering caused by climatic and aerodynamic effects.

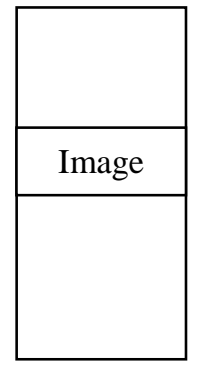

[The first part of this paper is aimed for the scale modelling and monitoring of climatic effects on the glassy medieval mosaic situated on the façade of St. Vitus Cathedral on Prague Castle. Second part is dedicated to characterization of material changes of polymeric coating protective layer exposed to aggressive environment.] 